\title{
O CÓdIGO DO CONSUMO E O ANTEPROJETO DE REFORMA DO DIREITO DAS OBRIGAÇÕES. QUE INFLUÊNCIA E QUE HARMONIZAÇÃO?*
}

\section{Gilles Paisant**}

Pontos-chaves: Para se abrir às "necessidades do tempo presente", o anteprojeto de reforma do direito das obrigações leva, notadamente, em conta as preocupações consumeristas - Vários dos seus artigos, que tratam da Reforma do Código Civil, mencionam o consumidor ou parecem inspirados pelo Código do Consumo - Situações de concorrência, ou, ainda, de contradições, aparecem em suas disposições - Métodos a pensar para uma boa harmonização entre o direito comum atualizado, expresso pelo anteprojeto e as leis especiais existentes ou, eventualmente, a serem reformadas.

Á época de seu bicentenário, nosso venerável Código Civil se encontra engajado em um importante movimento de reformas que o transforma a um ritmo constante.

Se as mais espetaculares entre elas - especialmente em vista dos princípios postos em 1804 - referem-se ao direito da família com, notadamente, a lei de 3 de Dezembro de 2001, sobre o direito do cônjuge sobrevivente e dos filhos adulterinos, a de 26 de Maio de 2004 sobre o divórcio ou, ainda, a resolução de 4 de Julho de 2005, sobre a filiação sem esquecer, naturalmente, a recente reforma do direito das sucessões ${ }^{1}$, está claro que a evolução da sociedade e as trocas econômicas não podiam deixar o direito das obrigações fora destas mudanças. A resolução $n^{\circ} 2006-346$ de 23 de Março de 2006, relativa à segurança ${ }^{2}$ atesta isso.

É verdade dizer que os operadores do direito parecem hoje divididos entre duas preocupações, aparentemente contraditórias: de um lado, adotar uma pausa num contexto geral de inflação legislativa, que acaba por ser fonte de instabilidade e de insegurança jurídica ${ }^{3}$, de outro lado, modernizar nosso direito das obrigações seguindo nossas próprias conveniências e, caso necessário, servir de fonte de inspiração a outras ${ }^{4}$ ao invés de se dever fundir num molde vindo de um outro lugar, num quadro, por exemplo, de uma "europanização" do direito dos contratos.

Nesse contexto, seremos gratos ao grupo de trabalho constituído pela iniciativa de Pierre Catalã por ter, durante o curso de outono de 2005, proposto ao Ministro da Justiça um rico "anteprojeto de reforma do direito das obrigações e do direito da prescrição"

\footnotetext{
* Texto originalmente publicado em 20 de setembro de 2006, na JCP/La Semaine Juridique n. 38 e traduzido por Ana Carolina Sousa (especializanda na Faculdade de Direito da UFRGS). Revisão e harmonização de Simone Regina Backes (Mestranda em Direito pela Université de Lausanne/Université de Saviè).

* Professor da Universidade de Savoie.

1 L. 11 2006-728, 23 junho de 2006:JO 24 junho de 2006, p.9513; JCP G 2006, III, 20003; JCPG 2006, I, 160 et 161, estudos R le Guidec, Ph. Simler et P. Hilt.

2 Ord. ${ }^{\circ} 2006-346$ de 23 de março de 2006:JO(jornal oficial) 24 de março de 2006, p.4475; JCP G 2006 supplément au n ${ }^{\circ} 20$, études 1 à 9 .

3 J. De Claussade, Sécurtité juridique et complexité du droit, Études et documents du conseil d'État : Doc. fr., 2006, p.229s.; R. Piastra, Trop de lois en France: D. 2006, p.1060; Veja também, La loi protège-t-elle encore le faible lorsqu'elle est aussi complexe, foisonnante et instable?: JCP G 2006, I, 121 .

4 P. Catalã, La genèse et le dessein du projet: RDC 2006, p. 17, <<Un projet portant le message de notre pays hors de nos frontières $>>$.

5 www.justice.gouv.fr/publicat/rapports.htm; vide, também, sobre este texto: RDC 2006, $\mathrm{n}^{\circ}$ spéc.(2006/1) e P.Catala, rápida visualização do direito das obrigações (Bref aperçu sur l'avant-projet de réforme du droit des obligations): D. 2006, p. 535.
} 
No espírito do Código de 1804, endereçando-se de "maneira indiferenciada a todo cidadão", esse anteprojeto se baseia no princípio segundo o qual convém deixar para outros códigos ou leis "a tarefa de arrumar a balança contratual com o objetivo de dar mais eficiência e segurança em função das situações jurídicas em causa e da utilidade social buscada" . A justo título, de fato, nesse trabalho, o contrato ocupa uma posição de destaque em cena

Mais precisamente, na medida em que o texto é proposto, se apresentando como um "código de ajustamento" 7 , e não de ruptura, compreende-se, nesse sentido, fazer prova "de

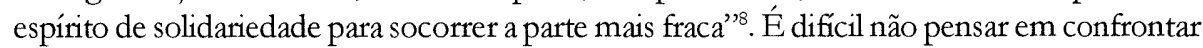
essas disposições com as leis especiais de proteção dos consumidores, seja para avaliar a influência dessas últimas (1)ou para julgar a compatibilidade delas (2).

1 - Evidentemente, na sociedade de consumo que nos caracteriza, os autores do anteprojeto não têm podido ficar insensíveis às preocupações consumeristas, tendo em vista suas intenções de responder " às necessidades do tempo presente".

A melhor prova disso é que, às vezes, o texto proposto é endereçado diretamente aos consumidores. Assim é o caso dos artigos 1122-2 e 1382-2. Pela primeira vez, depois de uma tentativa recente que restou infrutuosa ${ }^{10}$, os consumidores integrariam o Código Civil francês.

A primeira dessas disposições faz parte daquelas consagradas ao objeto. A título de defeito de equivalência entre as prestações, ela é relativa às cláusulas abusivas e redigida nos termos que seguem: "a cláusula que cria no contrato um desequilíbrio significativo em detrimento de uma das partes pode ser revisada ou suprimida a pedido deste, nos casos nos quais a lei a proteja com uma disposição particular, notadamente em sua qualidade de consumidor ou quando ela ainda não foi negociada".

Sem dúvida, esse artigo foi inspirado, como reivindicam expressamente seus autores ${ }^{11}$, pelos princípios $L a n d \grave{o}^{12}$, mas não se pode evitar a referencia à diretriz comunitária do 5 de abril de 1993, e ao atual artigo L 132-1, do Código do Consumo. Sem trocadilhos, tanto este último texto como aquele que é proposto agora, seguem um objetivo similar.

O artigo 1382-2 no sub-título sobre a responsabilidade civil é relativo às Convenções sobre a reparação. Ele prevê particularmente na sua alínea 2, que "na ausência de contraparte real, séria e claramente estipulada, um profissional não pode excluir ou limitar sua obrigação de reparar o dano contratual causado a um não profissional ou ao consumidor".

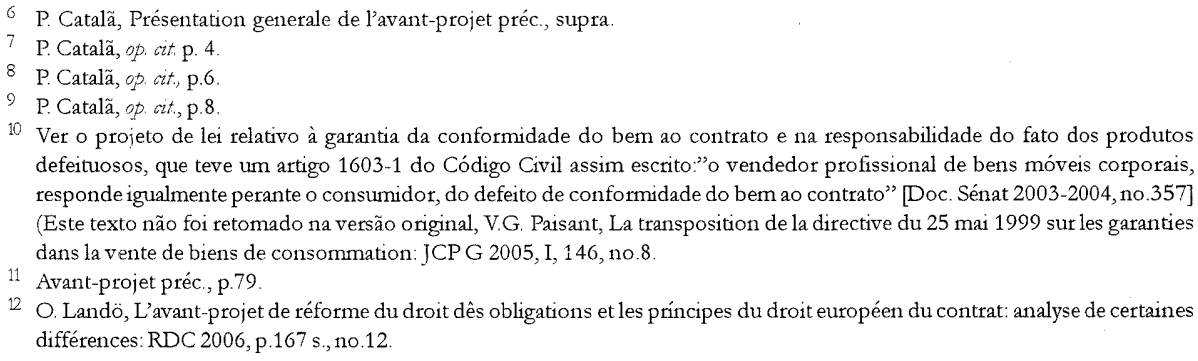

12 O. Landö, L'avant-projet de réforme du droit dês obligations et les príncipes du droit européen du contrat: analyse de certaines différences: RDC 2006, p.167 s., no.12. 
Os redatores confessam que essa disposição se inspira nas recomendações da Comissão das Cláusulas Abusivas ${ }^{13}$. Trata-se assim, de dar força de lei a estas recomendações que estariam ressaltadas nos trabalhos da Comissão, as quais, como sabemos, ainda não apresentavam nenhuma força obrigatória para os particulares ${ }^{14} \mathrm{Ou}$ autoridades públicas ${ }^{15}$.

Sem que o consumidor, desta vez, seja expressamente citado, outras disposições do anteprojeto parecem generalizar a todos os contratantes as preocupações consumeristas.

Sem pretender ser exaustivo, podemos começar por citar o artigo 1110, alínea 2, relativo à obrigação de informação. Esta obrigação é, em efeito, proposta em favor daquele que não somente "estava na impossibilidade de se informar por si mesmo", mas ainda, "legitimamente, pode confiar em seu co-contratante, em razão, notadamente, da natureza do contrato ou da qualidade das partes.". Essa disposição vem ao encontro daquelas do Código de Consumo, que, conscientes da inferioridade, particularmente técnica, do consumidor, impõe ao profissional, presumido como capacitado e competente, de colocar o primeiro, presumido ignorante, "na possibilidade de conhecer as características essenciais do bem ou do serviço" 16 .

Vamos ressaltar também as disposições dos artigos 1172 e seguintes, sobre interdependência dos contratos, uma vez que a execução de um "é necessária para a realização de uma operação conjunta.". Essa noção parece inspirada no mecanismo aplicado pela lei do 10 de janeiro de 1978, que, para contrariar a jurisprudência dada com fundamento do direito comum $^{17}$, estabeleceu nas operações de crédito pelo consumo, uma ligação jurídica entre o contrato de financiamento e o contrato financiado ${ }^{18}$, de maneira que, por exemplo, a resolução do segundo implica a resolução do primeiro ${ }^{19}$.

Na mesma ordem de idéias, quando o artigo 1140, alínea 1, dispõe que quando "a lei contratual foi estabelecida sob influência dominante de uma da partes, deve-se interpretar em favor da outra", podemos ver uma generalização da regra do artigo L. 133, alínea 2, do Código do Consumo, de acordo com a qual, em caso de dúvida, as convenções entre profissionais e consumidores, se interpretam no sentido mais favorável a esses últimos. Mas é verdade que, retornando na cronologia, esse texto se inspira, também, no ainda atual artigo 1162, do Código Civil, que, tal qual interpretado pela jurisprudência ${ }^{20}$ quer que, de forma geral, os contratos se interpretem contra aqueles a favor de quem foram redigidos.

Direito comum e direito especial fazem aqui, amplamente, dupla função, o que nos leva a indagar sobre a harmonização do anteprojeto com o código promulgado em 1993.

\footnotetext{
13 Avant-projet, préc.., p.149

14 Cass. 1 re civ., 13 nov. 1996: Bull. Civ. 1996, I, no.399; D. 1997, p.174, obs. Ph. Delebecque; Rtd civ. 1997, p.24, obs. J. Mestre.

$15 \mathrm{CE}$, Ge et $1^{\text {a }}$ ss-sect., 16 janv. 2006, no. 2006-069516, D. 2006, p.576; Contrats, conc. consom. 2006, comm. 117, par G. Raymond

16 C. Consom., art. L 111-1.

17 Por exemplo, Cass. 1ière civ., 20 nov. 1974: JCP G 1975, II, 18109, note J. Calais-Auloy.

8 C. Consom., art. L. 311-20s.

9 Comp. avant projet, art 1172-3

20 Cass. 1ière civ., 4 juin 1985: Bull civ. 1985, I, no. 175. - CA Colmar, 25 janvi. 1963: Gaz. Pal. 1963, 1, jurispr. P. 277
} 
2 - Sobre esse ponto, os princípios foram propostos pelo próprio anteprojeto. Expressão de um "direito comum atualizado"21, este último, como o Código de 1804, tem a vocação de reger todas as relações contratuais. $\mathrm{O}$ artigo 1103 propõe dessa forma: as regras gerais são aquelas do Código Civil, ao passo que as regras particulares a certas situações contratuais, sobretudo nas matérias referentes às relações de trabalho e à proteção dos consumidores, podem estar separadas.

Nesse sentido, o artigo 1110, alínea 2, prevê que "em certas convenções determinadas pela lei, o consentimento torna-se definitivo e irrevogável apenas depois da expiração de um prazo de reflexão ou arrependimento". Pensamos, evidentemente, no uso feito muitas vezes desses dois direitos no Código de Consumo, em particular.

Essa lógica de princípio à exceção, nem sempre é respeitada, e, portanto, ocorrem dificuldades e, notadamente, riscos de duplicidade, e, como vêm sendo ressaltado, riscos de ambiguidade ou, ainda mais grave, de contradições.

Os problemas apresentam-se primeiramente, quando o anteprojeto prevê que as regras especiais resultarão tanto de títulos particulares do próprio Código Civil como também de disposições resultantes de outros cádigos ou leis ${ }^{22}$.

Os dois artigos que, no anteprojeto, se referem expressamente aos consumidores, são reveladores dessas dificuldades.

O primeiro (art. 1122-2), sobre as cláusulas abusivas, prevê o pedido do consumidor ou da parte que não pode negociar o contrato, de revisão ou de supressão das estipulações que criem um desequilíbrio significativo contra ele. Por várias razões, sua combinação com as disposições do atual artigo L.132, alínea 1, do Código do Consumo, é problemática. Em primeiro lugar, há a questão da determinação do regime jurídico aplicável. Deve-se contentarse com a prescrição geral do texto proposto, nos casos em que o contrato não foi negociado e reservar o regime do artigo L.132, alínea 1, apenas aos consumidores? Essa distinção seria impraticável na medida em que, em regra geral, os profissionais não são capazes de negociar os contratos que concluem com os consumidores. A solução consistiria então em dizer que, em todos os casos, incluídos, portanto, as relações entre profissionais, o artigo 1122, alínea 2, reenvia às disposições do artigo L.132, alínea 1, pois esse é especifico aos contratos concluídos entre profissionais e consumidores ou não-profissionais... Em segundo lugar, a contradição prossegue pois, no texto proposto, só o resultado do desequilíbrio efetivo conta. Assim, fazemos também a abstração das cláusulas que teriam somente por objeto criar esse desequilíbrio significativo, sem, no entanto, conseguir. Em terceiro lugar, no anteprojeto, a sanção pelo abuso pode residir numa simples revisão da cláusula litigiosa, ao passo que o artigo L132, alínea 1, confome às prescrições comunitárias, priva a cláusula de toda a eficácia jurídica, como se ela não estivesse escrita. Em quarto lugar, ainda, essa sanção deverá ser aplicada conforme o pedido do próprio interessado, enquanto que, pela aplicação das disposições do Código do Consumo, derivadas da diretiva de 5 de abril de 1993, sabemos

\footnotetext{
$21 \mathrm{P}$. Calada, Présentation générale, préc

2 Avant-projet, art. 1103 , al. 2
} 
que a TJCE, notadamente numa decisão de 27 de junho de $2000^{23}$, se pronunciou a favor do poder de ofício do juiz ... E quid da possibilidade de proibir as cláusulas por decretos? Esse mecanismo seria reservado aos contratos de consumo? $\grave{A}$ evidência, os dois textos são dificilmente conciliáveis.

A mesma constatação pode ser feita com o artigo 1382, alínea 2, do anteprojeto sobre as cláusulas relativas à responsabilidade dos profissionais nos contratos concluídos com os consumidores, a qual prevê negar qualquer valor juridico à cláusula na ausência de contrapartida real e séria expressamente estipulada. Esta disposição geral é muito diferente daquela que deriva do artigo R. 132, alínea 1, do Código do Consumo, que entende não escritas, somente nas vendas, as cláusulas que fazem obstáculo ou diminuem os direitos de reparação do condumidor, nesse caso sem considerar a incidência de uma eventual contrapartida.

Mas as dificuldades da harmonização não estão somente ligadas ao fato de que o anteprojeto seja endereçado diretamente aos consumidores.

Citamos, a esse respeito, o artigo 1114, alínea 3. sobre o vício da violência, quando uma parte se enconta em estado de fraqueza, especialmente em razão da vulnerabilidade ou desigualdade econômica que ela sofre em comparação ao outro contratante. Essa disposição nos faz inevitavelmente pensar no abuso de fraqueza inscrito tanto Código de consumo ${ }^{24}$, qunato no Código Penal ${ }^{25}$, e o encontro dos textos é inevitável se queremos admitir que a fraqueza da pessoa, notoriamente o do consumidor, vem também de uma situação de ignorância. Poderíamos admitir, por exemplo, que o vício de consentimento, seja constituído quando a infração do Código de consumo ou do Código penal, será estabelecido?

Ainda no domínio das sanções, podemos também ver que, segundo o artigo 1110 da alínea 1, do anteprojeto, "a falta a uma obrigação de informação, sem intenção de enganar, engaja a responsabilidade daquele que era orbrigado a dar a informação". Ao contrário, em conseqüência, o dolo e o vício de consentimento, serão constituídos pela intenção de enganar. Ora, sabemos que, sem que tenha lugar de buscar a qual intenção correspondia a falta do profissional na sua obrigação de informar o consumidor, a Corte de Cassação pode admitir a sanção da nulidade do contrato. Um esclarecimento seria aqui também desejado.

Compreendemos que a adoção do anteprojeto da reforma, sem modificações internas e periféricas, seria fonte de conflitos com um grande número de disposições do Código de consumo $^{26}$. Uma harmonização desse texto, com leis especiais, aparece, portanto, necessária para evitar a criação de uma situação de concorrência conflitual.

23 TJCE (Tribunal de Justiça das Comunidades Européias), 27 juin 2000, aff. C-240/98: JGPG 2001-II, 10513, nota M. Carballo Fidalgo e G. Paisant; LPA 24 juill. 2001, p. 25, nota S. Hourdeau; RTD civ. 2001, p.878, obs. J. Mestre e B. Fages.

24 C. consom., art. L 122-8 es.

25 C. pén., art. 223-15-2.

26 Cass. 1ière civ., 7 déc. 2004, no. 01-11.823: Jurs-Data no.2004-026047; Bull civ. 2004-I, no.303; D.2005, p.75, obs. Rondey, JCP G 2005, II, 10160, nota N. Rzepecki; NPA 7 sept. 2005, p.16; RTD civ. 2005, p.389, obs. J. Mestre e B. Fages; RDC 2005, p.323, obs. D. Fenouillet. 
Tecnicamente, no ponto de vista do método, uma opção se apresenta a título principal: ou o Código de consumo é modificado para ter em conta as escolhas expressas no anteprojeto, ou, seguindo assim a tradição, extrairíamos do texto proposto todas as disposições visando particularmente osconsumidores para reservar o monopólio ao Código do consumo.

Essa última solução nos parece a preferivel, por estar em maior conformidade com os fundamentos e com o espírito do nosso direito de consumo que, para exprimir tanto a necessidade como a especificidade da proteção dos consumidores, foi além dos princípios do direito comum do Código Civil. O Código do consumo representa o receptáculonatural desse particularismo, da mesma maneira que o Código do trabalho exprime a especificidade das relações do trabalho.

Sem dúvida, podemos observar que a Alemanha, por exemplo, escolheu a solução inversa na sua lei de reforma do direito das obrigações, de 26 de novembro $2001^{27}$. Assim, o BGB inclui agora, uma definição do consumidor e das disposições particulares consagradas na sua proteção contratual. Mas, diferentemente da França, a Alemanha não adotou um Código do consumo. Se, portanto, por mimetismo, tomássemos o partido de deslocar no nosso Código Civil as disposições específicas à proteção dos consumidores, de um lado deveríamos questionar sobre a pertinência de manter em nossa ordem jurídica um Código de consumo, o que seria fonte de uma dispersão das regras que, por necessidade de coerência, juntamos em 1993, e, de outra parte, seria bom questionamos se outras regras contratuais específicas, excetuando-se as que tratam dos consumidores, não deveriam também, e pelas mesmas razões, ser reintegradas no Código Civil. Porque, em efeito, o que valeria por uma categoria de relações contratuais, não valeria para uma outra? Vamos pensar em termos de especificidade maior ou menor? Isso não teria sentido.

Uma outra pergunta é a de saber se não seria bom, em nome do hoje chamado "solidarismo contratual", generalizar, no conjunto das relações contratuais, certas disposições protetoras (especificamente, por exemplo, aquelas sobre as cláusulas abusivas) até agora reservadas a qualquer categoria de contratantes (em fato, os consumidores). Em caso afirmativo, o que vem de uma escolh a política bem respeitável, a nova regra geral teria lugar no Código Civil, substituindo a regra especial que perderia assim a sua razão de ser, sob reserva de conservar um particularismo residual.

Toda reforma do Código Civil sobre as obrigações nos parece assim chamar para uma harmonização desse direito comum com as leis especiais. De maneira mais específica, seria melhor, ao mesmo tempo em que pensamos - com razão- a reforma do Código Civil sobre as obrigações, começar também a reforma do Código do consumo por uma melhor harmonização das regras, e portanto, no interesse de todos que discutem algum conflito judicialmente. $O$ trabalho mereceria ter prosseguimento!

${ }^{27}$ V. C. Witz e F. Ranieri, La réforme du droit allemand des obligations: société de législation comparée, vol. 3, 2004. 